\title{
Retraction Note to: Akt2-Dependent Phosphorylation of Radixin in Regulation of Mrp-2 Trafficking in WIF-B Cells
}

\author{
Jo Suda ${ }^{1} \cdot$ Don C. Rockey $^{2} \cdot$ Serhan Karvar ${ }^{2}$
}

Published online: 9 December 2021

(c) Springer Science+Business Media, LLC, part of Springer Nature 2021

\section{Retraction to: Dig Dis Sci (2016) 61:453-463 https://doi.org/10.1007/s10620-015-3905-4}

The Editor-in-Chief has retracted this article. Concerns have been raised regarding 2 specific figures as follows:

- Figure 6: 2 of the 15 images within this panel figure for "Akt2 siRNA" and "Akt inhibitor" appear to be different parts of the same image, even though they were stated to represent two different experimental conditions.

- Figure 7a: this figure includes 20 lanes which were probed for four different rows of proteins or phosphorylated proteins (p-Akt, p-Radixin, Mrp-2, and 5-NT) under various conditions. For each p-Akt and 5-NT, there were two duplicates of the same blot image within the rows.

Although the authors reported that these mistakes were caused by human error, the original files documenting these figures are no longer available and the Research Integrity Officer at the Medical University of South Carolina has confirmed that the original files documenting these figures are no longer available. The Editor-in-Chief therefore no longer has confidence in the reliability of the data reported in the article. All authors agree to this retraction.

Publisher's Note Springer Nature remains neutral with regard to jurisdictional claims in published maps and institutional affiliations.

The original article can be found online at https://doi.org/10.1007/ s10620-015-3905-4.

Serhan Karvar

karvar@musc.edu

Jo Suda

jsuda@usc.edu

Don C. Rockey

rockey@musc.edu

1 Division of Gastrointestinal and Liver Diseases, Keck School of Medicine, University of Southern California, Los Angeles, CA, USA

2 Division of Gastroenterology and Hepatology, Department of Medicine, Medical University of South Carolina, 96 Jonathan Lucas Street, 803 CSB, MSC 623, Charleston, SC, USA 